\title{
Allocation of Greenhouse Gas Emission for Japan Large Emitting Industries under Kyoto Protocol by Grandfathering Rule Approach
}

\author{
Jeff Huang, and Ken Nagasaka
}

\begin{abstract}
In the recent years, Global Warming has become an increasingly popular topic in our society. Reduction of Greenhouse gas (GHG) emission and the speed of global warming are important issue that will affect the entire human race. The Kyoto Protocol has helped many countries to establish their own GHG emission reduction target, but has failed to help the participating countries to devise an appropriate allocation plan. This paper looks at the trend in Japan's GHG emission as well as examines its major contributors. Based on the historical performance; economic growth rate; potential factor; reduction target and traditional/updating grandfathering rule approach, the allocation of emission allowance among the high emitting industries in Japan was determined. According to the calculation results from both traditional/updating grandfathering rule approaches, Iron \& Steel; Paper \& Pulp and Cement industry are on track and expect to keep its emission generation level very close to the allocation cap established under the first commitment period of the Kyoto Protocol. Chemical industry is the only industry required to take significant reduction exercise now in order to keep its emission level within the allocation cap. Also from the allocation result, the Iron \& Steel industry will be rewarded more emission allowance based on the result from the updating grandfathering rule approach.
\end{abstract}

Index Terms-Greenhouse Gas (GHG) emission, Emission allowance allocation, kyoto protocol, grandfathering rule approach,

\section{INTRODUCTION}

The Kyoto Protocol, however, does not provide specific guidance to the participating countries on the allocation of its target to different sector/industry. Consequently, without allocating the appropriate target for each sector/industry, many countries relied heavily on each sector/industry to set up their own reduction target. This often caused the actual reduction performance as a whole to deviate from the established reduction target. This situation has also occurred in Japan. Under the Kyoto Protocol, Japan has made a commitment to reduce its emission level by $6 \%$ compared to its 1990 emission level. But until now, a clear allocation plan of emission allowance still remains undefined [3].

In this study, we began by identifying the high greenhouse gas emitting industry in Japan. Then we allocated target

Manuscript received September 29, 2011, revised September 30, 2011.

Jeff Huang and Ken Nagasaka are with Department of Electrical and Electronics, Tokyo University of Agriculture and Technology, Tokyo, Japan. (e-mail: weiweihuang88@hotmail.com; bahman.kermanshahi@gmail.com) emission allowances to these high emitting industries under the Kyoto Protocol period based on two different allocations approach (Traditional and Updating Grandfathering rule approach). In the conclusion, we analyzed the trends and necessary actions that need to be taken by these high emitting industries and compared their current/forecasting emission generation to their allocation targets.

\section{BACKGROUND}

\section{A. Trends in Japan's GHG Emission}

In 2008, Japan's GHG emission was 1282 million tons $\left(\mathrm{CO}_{2}\right.$ equivalent), representing a $6.2 \%$ increase in comparison to the 1990 level (base year of the Kyoto Protocol). This is a $12.2 \%$ gap compared to the $6 \%$ reduction target prescribed under the first commitment period of the Kyoto Protocol. Among the 6 different gases classified as GHG emission, Carbon dioxide was dominant and contributed on average $94 \%$ of Japanese GHG emission total during 1990-2008. This percentage has increased from $91 \%$ in 1990 to $95 \%$ at the end of year 2008. This is likely to continue to grow in the future [1], [2]. Since $\mathrm{CO}_{2}$ gas was dominant, most of the reduction policy/activity was targeting on $\mathrm{CO}_{2}$ emission reduction. This concept was also applied to our research. Therefore, we focused on $\mathrm{CO}_{2}$ gas under Japan's GHG emission reduction program.

According to the historical emission data, it was shown that in Japan the energy conversion was the largest emitting sector followed by industrial sector. The total amount emission generated by these two sectors contributed to around $65 \%$ of Japan national emission total from 1990-2008. The other $35 \%$ is attributed to the transportation; commercial and residential sector. The historical emission performance data also indicated that the Iron \& Steel, Chemical, Paper \& Pulp and Cement were the top four largest emitters in Japan's industrial sector. These top four emitting industries contributed nearly $62 \%$ of the industrial sector's total emission amount during 1990-2008 [1], [2]. Usually the emission generated by the industrial sector has been much more controllable and less controversial to the general public then the other sectors. Based on this characteristic, many countries have targeted the industrial sector first in their emission reduction program. In this paper, we also targeted the industrial sector and analyzed the necessary actions that need to be taken by them in order to keep their emission levels within the reduction target under the first commitment period of the Kyoto Protocol [1], [7]. 


\section{B. Kyoto Protocol Target Achievement Plan}

Under the Kyoto Protocol, Japan has a commitment to reduce its GHG emission level by 6\% compared to its 1990 level. In order to achieve this target, the Japanese Government has proposed the action plan named "Outline for Promotion of Efforts to Prevent Global Warming” in 1998. Under this action plan, the Japanese Government has specified the necessary emission reduction action/target for each Japanese sector that needs to be taken in order to achieve the $6 \%$ reduction target [2], [7]. In February 2005, the Japanese Government changed the name of this action plan to the "Kyoto Protocol Target Achievement Plan". Although the name has been changed, its contents are still exactly the same as before. Since the establishment of Target Achievement Plan in 1998, the Japanese Government has so far made three major revisions. The latest revision was started in November 2006. After nearly one and half year of reviews and discussions, the final revision was announced on February 2008. In this latest revision, the Plan indicated that Japan's amount of GHG emission reduction will be short by 20 to 34 million tons $\mathrm{CO}_{2}$ equivalent from its Protocol's target. However, the Kyoto Protocol target can be achieved if each sector takes additional measures to cut its current emission level [2], [3]. These additional measures were included in the latest revision, but mostly were voluntary action which depended on eco-conscientiousness of the citizens. Therefore, although Japan may be able to achieve the Kyoto Protocol target under the Target Achievement Plan, it still remains uncertain when the real market behavior is taken onto consideration.

Another main feature of the Target Achievement Plan was focus on the emission reduction of the industry sector. Due to economic growth, the GHG emission from the commercial; residential and transportation sector have been increasing rapidly since the early 1990's. Furthermore, emission generated by these sectors usually has been considered difficult to control, as it is mostly dependent on human activity. Therefore, most of countries did not include these sectors when considering their emission reduction program. On the other hand, the control of emission generated by energy conversion and the industrial sector could be performed more easily, and is less controversial to the general public. This makes it ideal for the government to design its emission reduction program around these two sectors. This situation has also occurred in Japan, large proportion of the emission reduction target relied on the industrial sector. According the latest revision of the Kyoto Protocol Target Achievement Plan, Japanese industrial sector was required to educe $11.3 \%-12.1 \%$ of the 1990 emission level under the Kyoto Protocol period. On the other hand, the commercial; residential and transportation sector was allowed to increase its emission level by $26.5 \%-27.9 \%$; $8.5 \%-10.9 \%$ and $10.3 \%-11.9 \%$ respectively [3], [8].

In this research, we have calculated the allocation of emission allowance for each of the high emitting industry in Japan. The calculation was based on the emission reduction target proposed under the Kyoto Protocol Target Achievement Plan.

\section{MEthodS}

\section{A. Traditional Grandfathering Rule Approach}

Historic grandfathering rule is a simple and straightforward allocation method that utilizes the historical performance data to produce a best estimate for the allocation of GHG emission allowance. This type of free allocation method was popular and has been welcomed by most of general public. Many of the European countries chose this approach to allocate its emission allowance [5], [6]. We have also applied this allocation method in our study to determine the allowance allocation among the high emitting industries in Japan under the first commitment of the Kyoto Protocol.

In our study, grandfathering allocation method allowed each regulated entity to receive a share of the total GHG emission allowance. This is equivalent to its share of total emissions from all regulated entities in a defined baseline year. In another word, the emission allowance allocated to a particular entity is equal to the emission of that particular regulated entity in the baseline year multiplied by the ratio of the emissions cap to total emissions in the baseline year. The formula is as followed [6]:

$\mathrm{EA}(\mathrm{i})=\mathrm{BS}(\mathrm{i}) * \mathrm{CF}(\mathrm{i})$

$\mathrm{CF}(\mathrm{i})=\mathrm{AT} / \mathrm{BST}$

where:

AT: Emission allowance total

EA(i): Allocation of emission allowance for regulated entity i BS(i): Baseline year emission for regulated entity $i$

BST: $\sum$ of baseline year emission for all regulated entities

$\mathrm{CF}(\mathrm{i})$ : Correction factor, which to make sure the summation from all entity's allocation is equal to the overall emission allowance total

The above formulae have shown that, the grandfathering allocation method distributes the emission allowance for each regulated entity from the historical performance. For example, if entity A generated 10 units GHG emission in the baseline year, then 10 units emission allowance will be allocated to this entity accordingly. However, due to the economic cycle, a particular baseline year data may not be the true representation of the overall performance for a particular entity in the past. We have adjusted the baseline year value by taking the average value of a selected time period [6]. Compared to the data selected from a particular year, this better captured the overall condition.

\section{B. Updating Grandfathering Rule Approach}

The traditional grandfathering rule approach for emission allocation only depends on the past emission level BS(i) as described in previous section. This allocation approach would allocate more emission allowance to the emitters with larger emission in the past. This approach may create moral hazard such that the emitters may be encouraged to generate larger emission now in order to obtain more allowance in the future allocation period. Therefore, minimization of moral hazard and fairer reward for the emitters are important issues to be considered when designing the allocation rule. Furthermore, the future development (growth rate) of 
sector/industry is not considered in the traditional grandfathering rule approach. This may lead to problem such as over-allocating situation. Therefore, individual economic growth rate for each sector/industry should be incorporated when allocating the emission allowance [9], [13]. Many of the European countries have already included the above considerations in their emission allocation approach. In this research, we applied the same methodology as Austria to determine the allowance allocation among the high emitting industries in Japan under the first commitment of the Kyoto Protocol. The formula for this updating grandfathering rule is as followed [11]:

$$
\begin{aligned}
& \mathrm{EA}(\mathrm{i})=\mathrm{BS}(\mathrm{i}) * \mathrm{PF}(\mathrm{i}) * \mathrm{GF}(\mathrm{i}) * \mathrm{CF}(\mathrm{i}) \\
& \mathrm{CF}(\mathrm{i})=\mathrm{AT} / \mathrm{BSTG}
\end{aligned}
$$

where:

\section{AT: Emission allowance total}

EA(i): Allocation of emission allowance for regulated entity $i$ BS(i): Baseline year emission for regulated entity $i$

PF(i): Potential factor for regulated entity i

GF(i): Growth factor for regulated entity $i$

BSTG: $\sum \mathrm{BS}(\mathrm{i}) * \mathrm{PF}(\mathrm{i}) * \mathrm{GF}(\mathrm{i})$ for all regulated entities

$\mathrm{CF}(\mathrm{i})$ : Correction factor, which to make sure the summation from all entity's allocation is equal to the overall emission allowance total

Potential Factor PF(i) is the index for indicating the potential of emission reduction for entity $i$ by analysing its emission data/pattern in the past. In this research, we applied the same method as Austria used in their National allocation plan. The formula for calculating the Potential factor for particular industry i as follow [11]:

$\mathrm{PF}(\mathrm{i})=\mathrm{Prs} * \mathrm{PFP}+\mathrm{Pg} * \mathrm{PFG}+\mathrm{Pf} * \mathrm{PFF}$

where:

PF(i): Potential factor of industry $i$

Prs: Percentage of total $\mathrm{CO}_{2}$ emission volume for industry $\mathrm{i}$, generated from processing emission

$\mathrm{Pg}$ : Percentage of total $\mathrm{CO}_{2}$ emission volume for industry $\mathrm{i}$, generated from natural gas emission

Pf: Percentage of total $\mathrm{CO}_{2}$ emission volume for industry i, generated from fossil fuel emission

PFP: Potential factor of processing emission

PFG: Potential factor of natural gas emission

PFF: Potential factor of fossil fuel emission

The Potential factor of processing emission (PFP) is assumed to equal 1 as defined under the National Allocation Plan in Austria. This value is also applied in this research. And for the other fuel emission such as PFG and PFF, the value can be determined by the following formula. This formula also obtained from National Allocation Plan in Austria [11].

$\mathrm{Y}=\mathrm{k} * \mathrm{x}+\mathrm{d}$

where:

Y: Potential Factor

$\mathrm{K}$ : Constant value, -0.00145 as defined under Austria National Allocation Plan

d: Constant value, 1.04 as defined under Austria National
Allocation Plan

$\mathrm{x}$ : $\mathrm{CO}_{2}$ emission factor $\left[\mathrm{t}-\mathrm{CO}_{2} / \mathrm{TJ}\right.$ ]

\section{RESUlt AND Discussion}

In this research, we took the average value of the 2000-2004 emission data to represent the baseline year. This value is used in the traditional/updating grandfathering allocation method to distribute the emission allowance among the four highest emitting industries in Japan. In addition, we have assumed these four industries would take full responsibility on the reduction target (11.3-12.1\%) of the industrial sector's commitment under the Kyoto Protocol Target Achievement Plan. We have also assumed the emission level from all other industries will remain constant (based on the 2008 performance) until the end of year 2012.

\section{A. Result under Traditional Grandfathering Rule Approach}

By applying the traditional grandfathering allocation method as described in last section, we have calculated the emission allocation for each of these four large emitting industries under the first commitment period of the Kyoto Protocol. According to the calculation result, the indirect $\mathrm{CO}_{2}$ emission allowance under the first commitment period of Kyoto Protocol for the Iron \& Steel; Chemical; Paper\& Pump and Cement industries were $144.01 ; 50.88 ; 26.39$ and $32.68 \mathrm{mt}$ respectively. The detailed results are given in Fig. 1 to Fig.4. as below

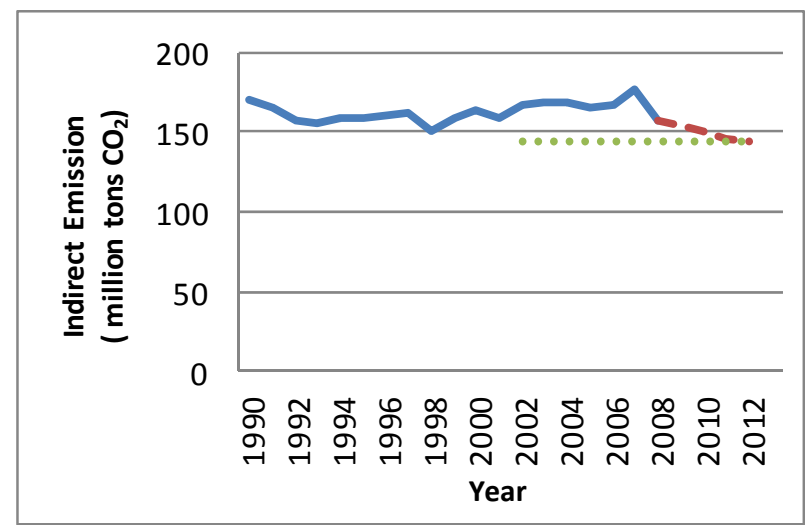

Fig. 1: Emission trend of the Iron \& Steel Industry
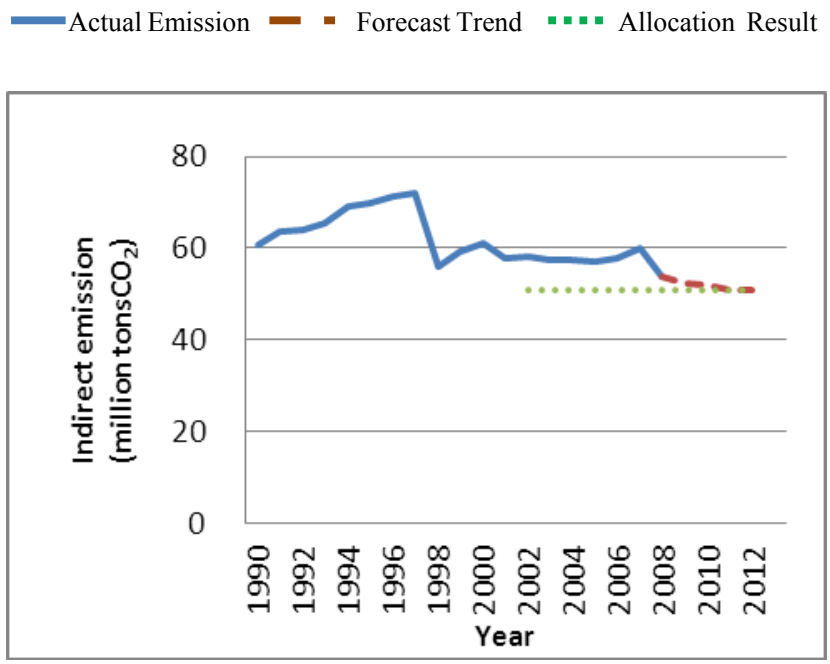

Fig. 2: Emission trend of the Chemical Industry

Actual Emission - - Forecast Trend " " - " Allocation Result 


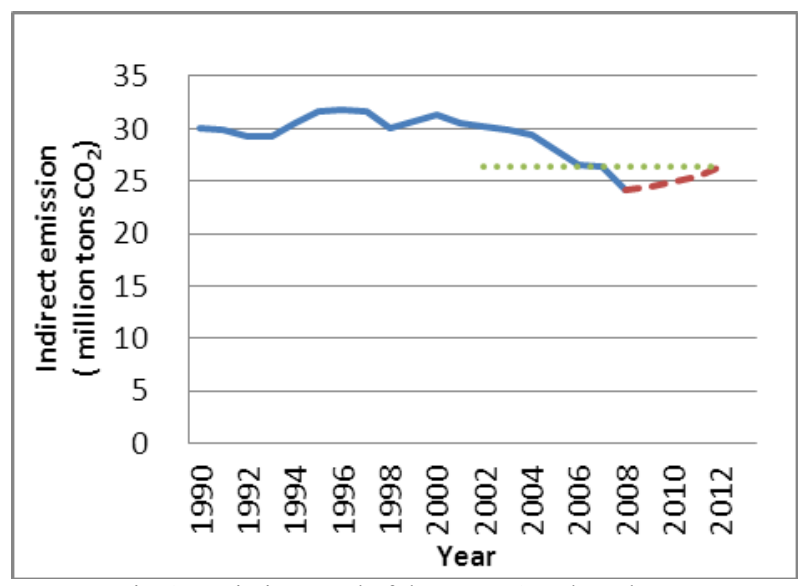

Fig. 3: Emission trend of the Paper \& Pulp Industry

-Actual Emission = " Forecast Trend " " " Allocation Result

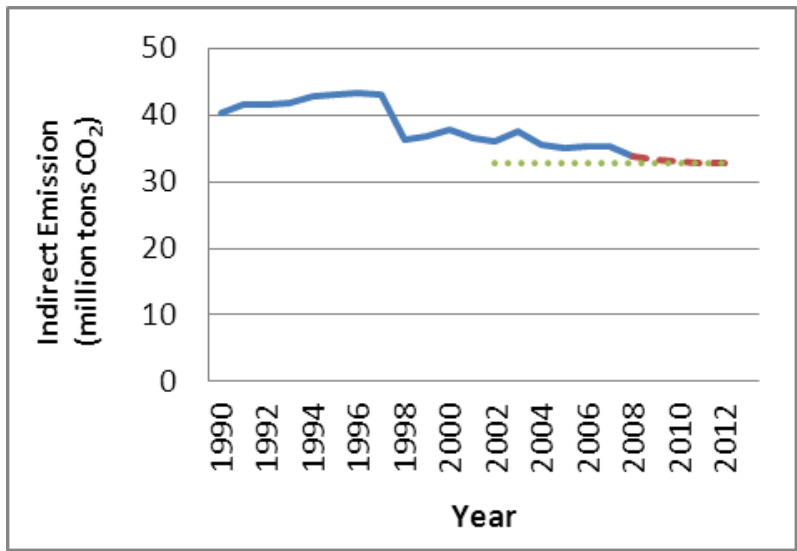

Fig. 4: Emission trend of the Cement Industry

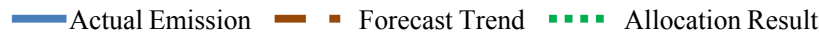

In TABLE I, we calculated the difference between the allocation result and the actual 2008 emission level for each of the main emitting industry in Japan. The result indicated the allowance allocation for the Paper \& Pulp industry was higher then their year 2008 actual emission generation. In another word, Paper \& Pulp industry would be allowed to generate more emission then their 2008 level under the Kyoto Protocol period. Conversely, the Iron \& Steel; Chemical and Cement industries would be required to reduce $8 \% ; 5.4 \%$ and $4.4 \%$ based on their 2008 emission level in order to keep their emission generation level under the allocation cap. Due to economic recession in 2008, Japanese industry has suffered seriously. Therefore, the 2008 emission level may not be an accurate representation of the true performance in the past. Based on this consideration, we have compared the allocation result to the 2007 emission level. When we compared the result to the 2007 emission level, the gaps have become larger for all industries. The surplus allowance for the Paper and Cement industries when compared to 2008 emission data have become deficit when compared to 2007 level. This result indicated that all of four large Japanese emitting industries would be required to take extra measures on emission reduction to keep the emission level under the allocation cap.
TABLE I: ALLOCATION RESULT AND 2008\&2007 INDIRECT EMISSION DATA FOR FOUR LARGE EMITTING INDUSTRIES IN JAPAN

\begin{tabular}{cccc}
\hline \hline Industry & $\begin{array}{c}\text { Allocation } \\
\text { result in 2012 } \\
\left(\mathrm{m} \text {-tons } \mathrm{CO}_{2}\right)\end{array}$ & $\begin{array}{c}\text { 2008 indirect } \\
\text { emission data } \\
\left(\mathrm{m} \text {-tons } \mathrm{CO}_{2}\right)\end{array}$ & $\begin{array}{c}\text { 2007 indirect } \\
\text { emission data } \\
\left(\mathrm{m} \text {-tons } \mathrm{CO}_{2}\right)\end{array}$ \\
\hline Iron \& Steel & 144.01 & 156.64 & 176.06 \\
Chemical & 50.88 & 53.75 & 60.15 \\
Paper \&Pulp & 26.39 & 24.17 & 26.47 \\
Cement & 32.68 & 34.08 & 35.98 \\
\hline \hline
\end{tabular}

m-tons $\mathrm{CO}_{2}$ : million tons $\mathrm{CO}_{2}$

In this research we have forecast the emission generation in 2012 for each Japanese emitting industry. The forecast was based on the forecasting production value and the proposed reduction target/scheme under the Kyoto Protocol Target Achievement Plan [1] [4]. According to the calculation result, the Iron \& Steel; Chemical; Paper \& Pump and Cement industry will expect to generate $154.59 ; 64.45 ; 24.42$ and $29.65 \mathrm{mt}$ of indirect $\mathrm{CO}_{2}$ emission respectively at the end of year 2012. When comparing the forecast to the allocation results derived earlier, the Iron \& Steel and Chemical industries are expected to generate more emission then their allocated amount at the end of year 2012. This implied that, these two industries would be required to take additional measures now to keep their emission generation level under the allocation cap during the Kyoto Protocol period.

TABLE II: ALLOCATION AND FORECSTNG INDIRECT EMISSION GENERATION RESULT FOR FOUR LARGE JAPANESE EMITTING INDUSTRI ES IN YEAR 2012

\begin{tabular}{ccc}
\hline \hline Industry & $\begin{array}{c}\text { Allocation result } \\
\text { in year 2012 } \\
\left(\mathrm{m} \text {-tons } \mathrm{CO}_{2}\right)\end{array}$ & $\begin{array}{c}\text { Forecast emission } \\
\text { in year 2012 } \\
\left(\mathrm{m} \text {-tons } \mathrm{CO}_{2}\right)\end{array}$ \\
\hline Iron \& Steel & 144.01 & 154.59 \\
Chemical & 50.88 & 64.45 \\
Paper \& Pulp & 26.39 & 24.42 \\
Cement & 32.68 & 29.65 \\
\hline
\end{tabular}

m-tons $\mathrm{CO}_{2}$ : million tons $\mathrm{CO}_{2}$

\section{B. Result under Updating Grandfathering Rule Approach}

Under the updating grandfathering rule approach, the parameters (baseline year data; potential factor; growth factor and compliance factor) for each allocated industry need to be determined in advance. In this research, the $\mathrm{CO}_{2}$ emission factor for natural gas and fossil fuel emission in Japan were $49.5 \mathrm{t}-\mathrm{CO}_{2} / \mathrm{TJ}$ and $90.6 \mathrm{t}-\mathrm{CO}_{2} / \mathrm{TJ}$ respectively. This is based on the publishing data available from Japan LP Gas Association. Based on these fuel emission data with formula 6 , the potential factor of natural gas and fossil fuel emission in Japan were 0.97 and 0.91 respectively as determined. By incorporating these potential factors with emission pattern of each industry presented from Energy balance table issued by Agency for Natural Resource and Energy, we can calculate the Potential factor for four highest emitting industries in Japan accordingly [11]. The results are given in the following TABLE III. 
TABLE III: EMISSION PATERN AND POTENTIAL FACTOR FOR FOUR LARGE JAPANESE EMITTING INDUSTRI ES IN YEAR 2012

\begin{tabular}{ccccc}
\hline \hline Industry & \% P.E & \% N.E & \% F.E & P.F \\
\hline \hline Iron \& Steel & 75 & 3.6 & 21.4 & 0.98 \\
Chemical & 85 & 9.3 & 5.7 & 0.99 \\
Paper \& Pulp & 29.6 & 1.6 & 68.8 & 0.93 \\
Cement & 75.3 & 0.3 & 24.4 & 0.97
\end{tabular}

\%P.E: Percentage of total emission generated from processing emission $\%$ N.E: Percentage of total emission generated from natural gas emission $\%$ F.E: Percentage of total emission generated from fossil fuel emission P.F: Potential Factor

Regarding the growth factor of industry in Japan, we obtained these figures from the report of Short-Term Energy Supply/Demand Outlook issued by IEEJ institution (The Institute of Energy Economic, Japan) [10]. According to this report, the forecasting growth rate for these four highest emitting industries during the Kyoto Protocol period as given in the following table:

TABLE IV: GROWTH RATE FOR FOUR LARGE JAPANESE EMITTING INDUSTRI ES DURING 2008-2012

\begin{tabular}{ccc}
\hline \hline Industry & Forecasting Production in & \% change during \\
(Main Product $)$ & 2012 & $(\%)-2012$ \\
& $(1,000$ tons $)$ & $+16.6 \%$ \\
\hline \hline Iron \& Steel & 112,490 & $-0.5 \%$ \\
$($ Crude steel $)$ & & \\
Chemical & 7,184 & $+2 \%$ \\
(Ethylene) & & \\
Paper \& Pulp & 27,465 & $-0.3 \%$ \\
$($ Paperboard $)$ & & \\
Cement & 58,011 & \\
$($ Cement $)$ & & \\
\hline \hline
\end{tabular}

Once we derived all the parameters, we can start to allocate the emission allowance for each industry in Japan under the first commitment period of the Kyoto Protocol by applying the updating grandfathering allocation formula as described in section III. According to the calculation result, the indirect $\mathrm{CO}_{2}$ emission allowance under the first commitment period of Kyoto Protocol for the Iron \& Steel; Chemical; Paper\& Pump and Cement industries were 155.56; 43.96; 25.31 and $291.7 \mathrm{mt}$ respectively. When we compared these allocation results to the 2007 emission level, it indicated that all of four large Japanese emitting industries would be required to take extra measures on emission reduction to keep the emission level under the allocation cap. On the other hand, when we compared to the allocation result derived from traditional grandfathering rule approach, Iron \& Steel industry is the only industry will reward more emission allowance. Chemical; Paper \& Pulp and Cement industries require to take more measures on emission reduction to keep the emission level under the allocation cap. The detailed results are given in TABLE V below
TABLE V: COMPARED THE ALLOCATION RESULTS TO 2007 INDIRECT EMISSION PERFORMANCE FOR FOUR LARGE JAPANESE EMITTING

\begin{tabular}{cccc}
\multicolumn{3}{c}{ INDUSTRIES } \\
\hline \hline Industry & $\begin{array}{c}2007 \mathrm{IE} \\
\left(\mathrm{m}-\text { tons } \mathrm{CO}_{2}\right)\end{array}$ & $\begin{array}{c}2012 \mathrm{AR}(\mathrm{TGA}) \\
\left(\mathrm{m} \text {-tons } \mathrm{CO}_{2}\right)\end{array}$ & $\begin{array}{c}2012 \mathrm{AR}(\mathrm{UGA}) \\
\left(\mathrm{m}-\text { tons } \mathrm{CO}_{2}\right)\end{array}$ \\
\hline \hline Iron \& Steel & 176.06 & 144.01 & 155.56 \\
& & $(-18.2 \% \mathrm{cr} .2007)$ & $(-11.6 \% \mathrm{cr} .2007)$ \\
Chemical & 60.15 & 50.88 & 43.96 \\
& & $(-15.5 \mathrm{cr} .2007)$ & $(-27 \% \mathrm{cr} .2007)$ \\
Paper \& & 26.47 & 26.39 & 25.31 \\
Pulp & & $(-0.4 \% \mathrm{cr} .2007)$ & $(-4.4 \% \mathrm{cr} .2007)$ \\
& 35.98 & 32.68 & 29.17 \\
& & $(-9.2 \% \mathrm{cr} .2007)$ & $(-19 \% \mathrm{cr} .2007)$ \\
\hline
\end{tabular}

m-tons $\mathrm{CO}_{2:}$ million tons of $\mathrm{CO}_{2}$

cr.: compared to

2007 IE: Indirect emission in year 2007

2012 AR (TGA): Allocation result in year 2012 by traditional grandfathering rule approach

2012AR (UGA): Allocation result in year 2012 by updating grandfathering rule approach

When comparing the forecast to the allocation results derived from updating grandfathering rule approach, Iron \& Steel; Paper \& Pulp and Cement industries are all very close. Only Chemical industry require to take large step for additional measure now to keep its emission generation level under the allocation cap during the Kyoto Protocol period.

TABLE VI: COMPARE THE FORECASTING EMISSION AND THE ALLOCATION RESULT FOR FOUR LARGE JAPANESE EMITTING INDUSTRI ES IN YEAR 2012 $\begin{array}{ccc}\text { Industry } & \begin{array}{c}\text { Forecasting indirect } \\ \text { emission in year 2012 }\end{array} & \begin{array}{c}\text { Allocation result in } \\ \text { Year 2012 (UGA) }\end{array}\end{array}$

(m-tons $\left.\mathrm{CO}_{2}\right) \quad\left(\mathrm{m}\right.$-tons $\left.\mathrm{CO}_{2}\right)$

\begin{tabular}{ccc}
\hline \hline Iron \& Steel & 154.59 & 155.56 \\
Chemical & 64.45 & 43.96 \\
Paper \& Pulp & 24.42 & 25.31 \\
Cement & 29.65 & 29.17 \\
\hline
\end{tabular}

m-tons $\mathrm{CO}_{2:}$ million tons of $\mathrm{CO}_{2}$

\section{CONCLUSION}

In this research, we began by analyzing the emission trends and then identified the high emitting industries in Japan. We then allocated the emission allowance to the four largest Japanese emitting industries under the Kyoto Protocol period by using two different types of allocation approach. The first allocation method is traditional grandfathering rule approach. This type of allocation method is totally relying on the historical emission performance. The second allocation method we applied is updating grandfathering rule approach. This type of allocation method is not only considering the historical performance, it also takes the ability of reduction potential and industry growth rate into the consideration when allocating the allowance.

According to the calculation results from both traditional/updating grandfathering rule approaches, the Iron \& Steel; Paper \& Pulp and Cement industry are on track and expect to keep its emission generation level very close to the 
allocation cap established under the first commitment period of the Kyoto Protocol. Chemical industry is the only industry required to take significant reduction exercise now in order to keep its emission level within the allocation cap. Also from the allocation result, the Iron \& Steel industry will be rewarded more emission allowance based on the result from updating grandfathering rule approach.

In this research, we applied the grandfathering rule approach to allocate the emission allowance. This type of allocation method was simple and straightforward but it does come with some drawbacks. For example, this type of allocation mechanism only considers the historical performance on each allocated industry individually. And this may created an unfair allocation between each sector and industry. For example the unit cost for reducing one unit of emission in industry A may be different compare to industry B. Such this type of consideration is not considering under grandfathering rule approach. Therefore, in the future study, a further analysis would be required to address this particular issue in more detail.

\section{REFERENCES}

[1] National Greenhouse Gas Inventory Report of Japan, Ministry of the Environment Japan Greenhouse Gas Inventory Office, 2011.

[2] J. Ogawa, "Revised Kyoto Protocol Target Achievement Plan Overview and History of Revision" IEEJ HP(2008/7), July 2008

[3] Kyoto Protocol Target Achievement Plan, Ministry of the Environment Government of Japan, March, 2008, Available:

[4] Japan's National Greenhouse Gas Emissions for Fiscal Year 2007(Japanese). Ministry of the Environment Japan Greenhouse Gas Inventory Office, 2011.

[5] C. Hood. "Free Allocation in the New Zealand Emissions Trading Scheme A Critical Analysis". Policy Quarterly, vol. 6, Issue 2, pp. 30-36, February 2010

[6] R. Betz, W. Eichhammer, J. Schleich. “ Designing National Allocation Plans for EU emissions trading - A Fiest Analysis of the Outcome".Energy \& Environment, vol.15, number3, pp.375-425, 2004

[7] Dr. F. C. Mattes, "Greenhouse Gas Emissions Trading Outline of an Emission Trading Scheme for Japan", Discussion Paper for WWF International, Berlin, September, 2004

[8] T. Morotomi. "Institutional Design for the Emission Trading System in Japan". The Kyoto Economic Review, 75(2), pp. 129-149, December ,2006
[9] I. Jegou, L. Rubini, "The allocation of Emission Allowances Free of Charge: Legal and Economic Considerations", ICTSD, Issue Paper No.18, Aug 2011

[10] S. Suehiro, K. Suzuki, T. Hachiuma, M. Kako, M. Sofukuwaki, K. Sugii "Short-Term Energy Supply/Demand Outlook" IEEJ , Energy General, Supply and Demand Outlook, September, 2011

[11] National Allocation Plan for Austria, Pursuant to Art .11 of the EZG, Federal Ministry of Agriculture, Forestry, Environment and Water Management, March, 2011.

[12] Y. Ayukawa, "Japan's Climate Policy Cap \& Trade is Essential" presented at the German-Japanese Workshop on Economic Instruments for Climate Protection, WWF Japan, January, 2007

[13] F. Mullins, J. Karas, “ EU Emissions Trading: Challenges and Implications of National Implementation" , RIIA , Sustainable Development Programme, November, 2013

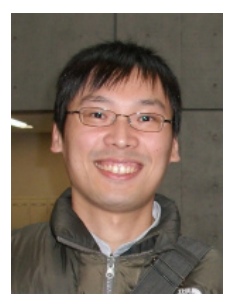

Jeff Huang, received the Master degree in electrical engineering from the Tokyo University of Agriculture and Technology. He is currently the $\mathrm{PhD}$ student in the Nagasaka Laboratory of Tokyo University of Agriculture and Technology. His research interests include renewable energy application; Climate and global change; emission market designed.

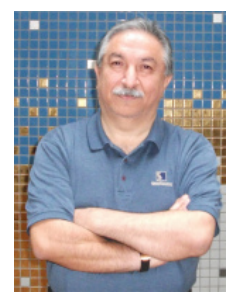

Ken Nagasaka, was born in 1956. He obtained his B.S, M.S and PhD degrees in Electrical Engineering from Nihon University (1985) and Tokyo Metropolitan University (1987, 1990), Tokyo, Japan. He worked as a Chief Researcher for Computer Software Development Company, Tokyo, Japan (1990-1991). He became a Visiting Professor at the University of Manitoba, Winnipeg, Canada (1991-1994). Then he worked as a Scientist at the Central Research Institute of Electric Power Industry (CRIEPI), Tokyo, Japan (1994-1998). He worked as an Associate Professor at the Department of Electrical Engineering of Tokyo Metropolitan University (1995-1998). Currently, he is an Associate Professor of Graduate School of Engineering at Tokyo University of Agriculture and Technology. Professor Nagasaka has published more then 150 scientific papers and one of his papers won a Paper-Prize of the Institute of Electrical Installation Engineers of Japan in 1991. In 2002, he received an award from the Ministry of Energy for his contribution to the International Power System Conference PSC-2002. His current research projects concern environmental energy engineering particularly power system analysis, wind power, load forecasting and application of intelligent system to power systems. Professor Nagasaka is a member of IEE, IEIE of Japan and a member of IEEE, International Neural Network Society of U.S.A. 